\title{
KEPUASAN PELANGGAN GERAI BATIK KERIS DI TINJAU DARI DIFERENSIASI PRODUK, BRAND IMAGE DAN PELAYANAN
}

\author{
Nura Iudita Kartikaningtyas, Eny Kustiyah, Djumali \\ Program Studi Manajemen Fakultas Ekonomi Universitas Islam Batik Surakarta \\ Email : nuraiuditakartika46@gmail.com
}

\begin{abstract}
This study aims to determine customer satisfaction at the Keris Batik Outlet. This type of research is quantitative descriptive. The population in this study used sample 100. Then the researchers used SPSS version 21 with quantitative analysis which included validity and reliability tests, classic assumption tests, multiple linear regression analysis, hypothesis testing with the $F$ test and t test and the coefficient of determination. Research results show that product differentiation, brand image, and service has a positive and significant effect on the customer satisfaction of Batik Keris Stores.
\end{abstract}

Keywords: Customer Satisfaction, Product Differentiation, Brand Image, Service.

\section{PENDAHULUAN}

Perkembangan usaha pada era globalisasi menggalami pertumbuhan yang sangat signifikan maka dari itu suatu perusahaan mempunyai trobosan untuk bisa bertahan dengan komoditas pelaku usaha lainnya, Gerai Batik Keris yang selalu berinovasi dengan produk barunya agar dapat mengikuti trend dan selera konsumen yang ada pada saat itu maka Gerai Batik Keris mempunyai produk yang bermacam - macam bukan hanya kain batik saja melainkan ada tas, lukisan, dompet, kipas, menong - menong, album simfoni yang terjual di seluruh toko yang tersebar di seluruh Indonesia dengan menambahkan Cafe pada toko agar pelanggan merasa tidak jenuh dalam melakukan transaksi saat menunggu maka dengan itu akan menciptakan Kepuasan Pelanggan. Merk atau Brand yang melekat pada konsumen tentang Batik Keris menambah nilai tambah pada barang atau produk yang dikeluarkan maka dari itu Batik Keris selalu memberikan produk yang menrik agar berkesan pada benak pelanggan yang melakukan pembelian dengan merk Batik Keris.

Menurut (Dejewata, Kumanji,Abdullah 2014) yang dimaksud dengan diferensiasi Produk ialah produk baru yang bervariasi dengan produk sebelumnya yang telah ada di pasaran yang dimaksudkan untuk menarik konsumen baru. Menurut Junior Andi, 2015 Para pelaku usaha harus benar-benar memahami kebutuhan pelanggan karena pelanggan memiliki kecenderungan menentukan produk yang di pilih sesuai kebutuhan pada akhirnya konsumen akan merasa puas.

Hanif (2011) juga mengungkapkan dengan adanya brand image maka perusahaan dapat memenuhi permintaan pelanggan sehingga konsumen dapat mendapatkan produk tersebut setiap saat dan tanpa syarat.

Menurut Tjiptono (1997) kualitas pelayanan yang maksimal adalah harapan dan pengendalian dari kesempurnaan untuk mencukupi kebutuhan pelanggan. Putra (2011) menyatakan dimensi kualitas jasa ada 5 yaitu dapat dipercaya oleh konsumen, bersikap tanggap terhadap konsumen, menunjukkan kesungguhan, dapat menjamin kepuasan konsumen, pelayanan 
bersifat nyata.

Kotler dan Armstrong (2008) pengertian dari kepuasan pelanggan ialah tanggapan perilaku yang di perlihatkan oleh konsumen dengan cara memperhitungkan kinerja yang dihasilkan dengan harapan. Jika hasil didapatkan dibawah harapan, yang terjadi pelanggan merasa kecewa dan merasa tidak puas begitu juga sebaliknya jika sesuai dengan harapan maka pelanggan akan merasa puas.

Berdasarkan penjelasan yang sudah diulas diatas maka pendapat peneliti layak untuk melakukan penelitian Kepuasan Pelanggan Gerai Batik Keris Di Tinjau Dari Diferensiasi Produk, Brand Image Dan pelayanan.

\section{LANDASAN TEORI}

Menurut (Junior Andi, 2015) yang di maksud dengan Diferensiasi Produk ialah aktivitas yang dilakukan perusahaan untuk menghasilkan serta memasarkan suatu produk baru dari tawaran pesaing. Perbedaan produk dalam hal ini memiliki keunggulan nilai dan manfaat lebih untuk mencukupi kebutuhan pelanggan.

Menurut (Sutopo \& Widiaswara 2017) terciptanya brand image (citra merk) ialah saat konsumen mendapatkan penggalaman yang menyenangkan dengan produk. Brand Image perusahaan yang memuaskan merupakan keunggulan dalam berkompetisi yang berpenggaruh pada tingkatan yang positif terhadap kepuasan pelanggan.

Menurut (Septiyawati Eliya, 2017) pelayanan yang maksimal harus selalu diperhatikan supaya dapat tetap bisa menggikuti peraingan dengan perusahaan lain dan tetap menjadi pilihan pelanggan. Pelayanan yang memuaskan akan menghasilkan dampak pada tingkat penilaian kesenangan konsumen akan terpenuhi harapan konsumen tersebut.

\section{METODE PENELITIAN}

Dalam hal ini peneliti menggunakan penelitian kuantutatif deskriptif. Lokasi penelitian adalah Gerai Batik Keris yang beralamatkan di Cemani, Kecamatan Grogol, Kabupaten Sukoharjo Jawa Tengah 57191. Waktu penelitian ini dilaksanankan pada bulan Oktober, November dan Desember 2019 (selama 3 bulan). Peneliti menggambil populadi dari Pelanggan Gerai Batik Keris yang berjumlah tak terhingga. Teknik sampling yang di gunakan dalam penelitian ini ialah teknik sampling purposive sampling. Peneliti mengambil sampel dari pelanggan Gerai Batik Keris yang melakukan transaksi pembelian di Gerai Batik Keris sesuai dengan kriteria yang di butuhkan dalam penelitian dan dapat di jadikan responden sebanyak 100. Analisis data yang di gunakan peneliti ialah dengan uji asumsi klasik, regresi liniear berganda dan uji hipotesa.

\section{HASIL DAN PEMBAHASAN}

\subsection{Analisa Data}

a. Uji Koefisien determinan (

Hasil dari analisis koefisien determinasi yang dihitung menggunakan software SPSS 21 didapatkan nilai adjust $\mathrm{r}$ square sebesar 0,240 atau 24\%. Kesimpulannya adalah Kepuasan Pelanggan Gerai Batik Keris dipengaruhi oleh variabel diferensiasi produk, brand image, dan pelayanan sebesar 24\%. Sedangkan untuk pengaruh sisanya $76 \%$ dihasilkan oleh variabel diluar dari penelitian yang dilakukan. 
b. Uji regresi linear berganda

Didapatkan hasil analisis regresi berganda yang di hitung menggunakan aplikasi SPSS 21 dapat di simpulkan:

$$
\mathrm{Y}=10,486+0,192 \mathrm{X} 1+0,229 \mathrm{X} 2+0,101 \mathrm{X} 3+\mathrm{e}
$$

Didapatkan nilai konstanta sebesar 10,486 berarti bila variabel diferensiasi produk, brand image, dan pelayanan sama dengan nol, maka variable kepuasan pelanggan sebesar 10,486.

Hasil dari koefisien diferensiasi produk terhadap kepuasan pelanggan sebesar 0,192. Kesimpulanya apabila diferensiasi produk naik maka kepuasan pelanggan juga meninggkat.

Apabila variabel brand image meningkat satu satuan maka mengakibatkan peningkatan pada variabel kepuasan pelanggan sebesar 0,229 satuan dan begitu juga sebaliknya, apabila variable brand image menurun satu tingkatan akan menurunkan kepuasan pelanggan sebesar 0,229 .

Apabila variabel pelayanan meningkat maka akan mengakibatkan peningkatan pada variabel kepuasan pelanggan sebesar 0,101 satuan dan begitu juga sebaliknya, apabila variabel pelayanan menurun satu tingkatan akan menurunkan kepuasan pelanggan sebesar 0,101 .

c. Uji Asumsi Klasik

1) Hasil Pengujian Uji Normalitas

Hasil dari perhitungan normalitas kolmogorov smirnov menggunakan aplikasi SPSS versi 21:

\begin{tabular}{|l|l|l|l|}
\hline Variabel & Kolmogorov-Smirnov Z & Signifikansi & Batas \\
\hline Unstandardized & 0,568 & 0,904 & $>0,05$ \\
Residual & & & \\
\hline
\end{tabular}

Hasil perhitungan dari uji Kolmogorov-Smirnov disimpulkan bahwa nilai p-value $0,904<\propto=0,05$, sehingga disimpulkan terdistribusi normal atau data yang dihasilkan normal.

2) Uji Multikolineritas

Hasil dari pengujian multikolineritas menggunakan aplikasi SPSS versi 21:

\begin{tabular}{|l|l|l|}
\hline Variabel & Tolerance & VIF \\
\hline Diferensiasi Produk & $\mathbf{0 , 9 3 0}$ & $\mathbf{1 , 0 7 5}$ \\
\hline Brand Image & $\mathbf{0 , 9 5 5}$ & $\mathbf{1 , 0 4 7}$ \\
\hline Pelayanan & $\mathbf{0 , 9 7 2}$ & $\mathbf{1 , 0 2 9}$ \\
\hline
\end{tabular}

Tabel 2 Hasil Uji Multikorelitas 
Tabel uji multikolineritas didapatkan nilai tolerance lebih dari 0,1 dan didapat hasil VIF tidak > 10, model dari regresi pada penelitian yang dilakukan tidak terjadi multikolineritas.

3) Uji Heterokedastisitas Hasil dari pengujian Heterokedastisitas menggunakan aplikasi SPSS versi 21:

Tabel 3 Hasil Heterokedastisitas

\begin{tabular}{|l|l|l|}
\hline Variabel & Sign. & Batas \\
\hline Diferensiasi Produk & 0,263 & $>0,05$ \\
\hline Brand Image & 0,615 & $>0,05$ \\
\hline Pelayanan & 0,400 & $>0,05$ \\
\hline
\end{tabular}

Dari tabel hasil perhitungan variabel $\mathrm{x} 1, \mathrm{x} 2$, dan $\mathrm{x} 3$ yaitu diferensiasi, brand image dan pelayanan memperoleh nilai signifikansi yang > dari 0,05. Disimpulkan ketiga variabel dari penelitian yang dilakukan dapat dikatakan telah lolos uji heteroskedastisitas.

d. Uji Hipotesa

1) $\mathrm{Uji} F$

Dapat disimpulkan hasil dari olah data diatas, didapatkan nilai $\mathrm{f}$ hitung sebesar 11,400 > 2,70, dan hasil signifikansi memiliki nilai 0,000 < 0,05. Dapat disimpulkan H0 ditolak, artinya diferensiasi produk, brand image dan pelayanan mempunyai pengaruh terhadap variabel kepuasan pelanggan yang signifikan serta simultan.

2) Uji t

Variabel diferensiasi produk memperoleh nilai t hitung sebear $(3,555)<(1,984)$ nilai signifikansi $0,001>0,05$ berarti $\mathrm{H}_{0}$ diterima. Kesimpulannya adalah variabel diferensiasi produk berpengaruh positif serta signifikan terhadap kepuasan pelangan.

Nilai hasil dari brand image sebesar $(3,234)<\quad(1,984)$ nilai signifikansi sebesar $0,002>0,05$ berarti $\mathrm{H}_{0}$ diterima. Kesimpulannya adalah variabel brand image berpengaruh positif dan signifikan terhadap kepuasan pelangan.

Hasil dari pelayanan memperoleh nilai $(1,484)<(1,984)$ nilai signifikansi sebesar $0,141>0,05$ berarti $\mathrm{H}_{0}$ ditolak. Kesimpulannya adalah variabel pelayanan berpengaruh positif dan akan tetapi tidak signifikan terhadap kepuasan pelangan.

\subsection{Pembahasan}

Nilai statistik dari penelitian ini menunjukkan perolehan nilai f hitung sebesar 11,400 dan nilai f tabel sebesar 2,7 signifikansi 0,000. Disimpulkan nilai f hitung > nilai $\mathrm{f}$ tabel dan signifikansi < dari 0,05. Dengan demikian maka hasilnya adalah diferensiasi produk, brand image dan pelayanan mempunyai pengaruh yang simultan terhadap kepuasan pelanggan Gerai Batik Keris.

Penelitian menggunakan analisis statistik menunjukkan secara parsial vaiabel 
diferensiasi produk tidak ada pengaruh signifikan terhadap variabel kepuasan pelanggan. Dibuktikan dengan perhitungan 3,555> 1,984, nilai signifikansi 0,001>0,05. Dapat ditarik kesimpulan Diferensiasi Produk di Gerai Batik Keris mempunyai penggaruh positif serta signifikan terhadap Kepuasan Pelanggan.

Penelitian menggunakan analisis statistik memperoleh nilai 3,234>1,984 nilai signifikansi $0,002<0,05$. Disimpulkan Brand Image berpengaruh signifikan terhadap kepuasan pelanggan di Gerai Batik Keris.

Hasil dari penelitian menggunakan analisis statistik menunjukkan bahwa secara parsial Pelayanan dan tidak terjadi pengaruh signifikan dari kepuasan pelanggan. Dibuktikan dengan nilai $1,484<1,984$, nilai signifikansi $0,141>0,05$. Disimpulkan variabel pelayanan berpengaruh positif serta tidak signifikan kepada variabel kepuasan pelangan.

\section{KESIMPULAN DAN SARAN}

\subsection{Kesimpulan}

Hasil dari penelitian ini adalah

a. Diferensiasi Produk, Brand Image dan Pelayanan mempunyai pengaruh positif serta signifikan secara simultan terhadap Kepuasan Pelanggan Gerai Batik Keris.

b. Diferensiasi Produk berpengaruh positif dan signifikan terhadap Kepuasan Pelanggan Gerai batik Keris, semakin bertambahnya variasi produk yang di keluarkan maka pelanggan akan memiliki berbagai pilihan.

c. Brand Image mempunyai pengaruh positif serta signifikan terhadap Kepuasan Pelanggan Gerai batik Keris, semakin baik pandangan atau penilaian pelanggan terhadap brand image pada Gerai Batik Keris maka harus di menjaga mutu dan kepercayaan masyarakat terhadap Gerai Batik Keris.

d. Pelayanan mempunyai pengaruh positif dan tidak berpengaruh signifikan untuk Kepuasan Pelanggan Gerai Batik Keris, pelayanan di lakukan kepada pelanggan dengan ramah akan memberikan kepuasan dan kesan kepada konsumen maka akan melakukan pembelian ulang.

\subsection{Saran}

Setelah mempelajari penelitian ini, serta mempelajari pembahasan dan kesimpulan, berikut adalah saran dari peneliti untuk perusahaan:

a. Gerai Batik Keris di harapkan bisa selalu berinovasi dalam setiap produk yang dikeluarkan, agar konsumen mempunyai variasi pilihan yang ada menurut selera masing masing.

b. Gerai Batik Keris selalu menjaga brand image atau citra merk sehingga produk yang dijual dapat menarik kepuasan pelanggan dalam setiap pembelian produk. Hal tersebut bertujuan untuk menjaga citra perusahaan terutama menjaga reputasi agar menjadi pilihan utama pelanggan.

c. Gerai Batik Keris di harapakan tetap mempertahankan Pelayanan yang maksimal agar konsumen merasa puas dan yakin untuk melakukan transaksi pembelian ulang. 


\section{DAFTAR PUSTAKA}

Farianti, Kharnolis,( 2018 ) “Kepuasan Konsumen Di Batik Tulis COLET Sutrisno Jombang”, Jurnal Tata Busana Hal 114 - 119 Universitas Negeri Surabaya, Volume 07 Nomor 02, Mei 2018.

Junior Andi ( 2015 ) "Pengaruh Diferensiasi Produk Terhadap Kepuasan Pelanggan" Lolita, Suharyono , Fanani ( 2018 ) "Pengaruh International Brand Image Terhadap Kepuasan Dan Dampaknya Pada Loyalitas Pelanggan (Studi Pada Pelanggan Sushi Tei Yogyakarta )”, Jurnal Administrasi Bisnis ( JAB ) Vol. 64, No.1, November 2018.

Septyawati Eliya ( 2017 ) “ Analisis Pengaruh Pelayanan, Kualitas Produk dan Promosi Terhadap Keputusan Pembelian Konsumen di Toko Batik Keris Nonongan Surakarta " Magistra , No. 99, Maret 2017.

Puung, Fudholi , Dharmmesta ( 2014 ) “Analisis Pengaruh Kualitas Pelayanan Pada Kepuasan dan Loyalitas Pelanggan Di Salon Spa ”, Jurnal Manajemen Universitas Gajah Mada Yogyakarta.

Harfani Rachmad ( 2014 ) "Analisis Pengaruh Citra Merk Dan Kepuasan Pelanggan Terhadap Loyalitas Pelanggan SIM Card Telkomsel ( Studi Kasus Pada Masyarakat Tangerang Selatan ) ”, Jurnal Manajemen Universitas Islam Negeri Syarif Hidayatullah Jakarta.

Pusparani, Rastini ( 2014 ) “Pengaruh Kualitas Produk Dan Brand Image Terhadap Kepuasan Konsumen Dan Loyalitas Pelanggan Kamera Canon Digital Single Lens Reflex (DSLR) Di Kota Denpasar", Jurnal Managemen Universitas Udayana, Vol 3, No 5, 2014.

Anastuti, Arifin Zainul, Wilopo ( 2014 ) "Pengaruh Diferensiasi Produk Terhadap Kepuasan Pelanggan ( Survei pada Mahasiswa Pengguna I Phone di Universitas Brawijaya Malang ) ", Jurnal Administrasi Bisnis (JAB), Vol 7, No 1, Januari 2014.

Reski, (2016) "Pengaruh Diferensiasi Produk dan Citra Merk Smarthpohe Samsung Terhadap Kepuasan Konsumen di Kota Makassar", Jurnal Manajemen Universitas Islam Negeri Alauddin Makassar, 2016.

Lubis, Andayani, (2017) "Pengaruh Kualitas Pelayanan (Service Quality) Terhadap Kepuasan Pelanggan PT Sucofindo Batam", Journal of Bussiness Administration, Vol.1 , No. 2, September 2017.

Iqbal, Murni, Sulistyowati (2018), "Analysis Of The Influence Or Brand Image And Customer Value On Customer Satisfacation And Its Impact On Customer Loyalyts" , International Journal of Ekonomics, Business and Management Research, Vol. 2, No 04, 2018.

Agyapong Gloria, (2011), "The Effect of Service Quality on Customer Satisfaction in the Utility Industry - A Case of Vodafone (Ghana)" , International Journal of Business and 
Management, Vol. 6, No 5, May 2011.

Jamaludin, Ruswanti Endang, 2017 "Impact of Service Quality and Customer Satisfaction on Customer Loyalty: A Case Study in a Private Hospital in Indonesia"

Puri, Riyan Mega 2017, "The Effect of Brand Image on Customer Satisfaction and Customer Loyalty For Wardah Local Cosmetic (Wardah Cosmetic)"

Istiatin. 2017. Metodologi Penelitian. Surakarta: UNIBA

Pawenang 2011. Pengantar ekonometrika. Surakarta: UNIBA 